\title{
Comparative performance of bench and portable near infrared spectrometers for measuring wood samples of two Eucalyptus species (E. pellita and E. benthamii)
}

\section{C.P. Diniz, ${ }^{a, *}$ D. Grattapagliab and L.F. de Alencar Figueiredo ${ }^{a}$}

aUniversidade de Brasília, Campus Universitário Darcy Ribeiro, Instituto de Ciências Biológicas, Departamento de Botânica, Asa Norte, CEP 70910-900, Brasília, DF, Brazil

bEmbrapa Recursos Genéticos e Biotecnologia, Parque Estação Biológica, CP 02372, CEP 70770-900, Asa Norte, Brasília, DF Brazil.

E-mail: carolina.pdiniz@gmail.com

The well-established and ever-growing applications of near infrared (NIR) spectroscopy for wood science and technology using bench spectrometers is unquestionable. However, the increasing interest in using portable spectrometers due to their perceived advantages raises the question of how good are they? In this work, we acquired spectra from wood sawdust samples of two Eucalyptus species, E. pellita and E. benthamii, totaling 1200 individual trees sampled in experimental breeding populations. Spectra were acquired in parallel using a bench spectrometer (FOSS NIRSystems 5000) and a portable instrument (Viavi MicroNIR1700). Spectra acquisition on the bench spectrometer had a longer wavelength (1100-2500 nm versus $908-1700 \mathrm{~nm})$ and a shorter absorbance profile. Principal component analysis on the spectral data of both instruments was not able to clearly separate the two species suggesting some level of overlapping distributions of the chemical composition of their respective wood properties. Linear discriminant analysis, however, had excellent accuracies with the bench spectrometer ( 99\%), showing significantly better discrimination than the one obtained with the portable one ( 93\%). Similarly, partial least square discriminant analysis showed correlations ( $r$ ) around 0.96 and standard errors of calibration (SEC) and of cross validation (SECV) lower than 0.155 on the bench instrument, while the portable spectrometer had $r \sim 0.88$ with SEC and SECV below 0.235. Although the bench instrument showed a better performance, the parameters estimated with the portable spectrometer were very satisfactory given its intrinsic limitations in robustness and handling needs. Chemical analyses for lignin content are in progress which, combined with data transformation and selection of spectra regions, could put the two instruments on similar performance grounds. These results are particularly relevant for rapid and simple wood phenotyping applications in advanced tree breeding operations.

\section{Introduction}

Eucalyptus is the largest genus in the Myrtaceae family, currently including 822 described species. ${ }^{1}$ Most species from this genus are native to Australia ${ }^{2}$ and some are widely used for commercial and industrial purposes. Commercial eucalypt species are model woody plants because of their high adaptability and fast growth rate in tropical climates, ${ }^{3}$ especially E. grandis and E. globulus upon which breeding programs on tropical and temperate regions, respectively, are mainly based. Eucalyptus benthamii and E. pellita on the other hand, despite their fast growth, are yet to be more widely adopted species. While E. benthamii displays resistance to periodic frosts in subtropical regions, ${ }^{4}$ E. pellita is particularly interesting for harsh tropical climates ${ }^{5}$ due to its heat tolerance, and resistance to some tropical pest and diseases. ${ }^{6}$ These two species used in hybrid breeding with E. grandis show great potential to expand high productivity plantations

\section{Correspondence}

C.P. Diniz (carolina.pdiniz@gmail.com)

doi: 10.1255/nir2017.031

Citation: C.P. Diniz, D. Grattapaglia and L.F. de Alencar Figueiredo,

"Comparative performance of bench and portable near infrared spectrometers for measuring wood samples of two Eucalyptus species (E. pellita and $E$. benthamii)", in Proc. $18^{\text {th }}$ Int. Conf. Near Infrared Spectrosc., Ed by S.B. Engelsen, K.M. Sørensen and F. van den Berg. IM Publications Open, Chichester, pp. 31-38 (2019). https://doi.org/10.1255/nir2017.031

\section{(c) 2019 The Authors}

This licence permits you to use, share, copy and redistribute the paper in any medium or any format provided that a full citation to the original paper is given, the use is not for commercial purposes and the paper is not changed in any way.

ISBN: 978-1-906715-27-4 
to areas currently considered marginal due to limiting environmental regimes.

Eucalyptus wood is mostly composed by cellulose (68-78\%), lignin (19-23\%) and hemicellulose ( 20\%). ${ }^{7,8}$ Cellulose is mainly used to produce Kraft pulp and paper products. ${ }^{9}$ The main use of highly lignified wood in the industry is for biomass, roundwood and wood-based panels' production. ${ }^{10}$ Eucalyptus wood lignin contains syringyl (S) and guaiacyl (G) monomers ${ }^{11}$ and the higher syringyl to guaiacyl (S/G) ratio, the cheaper it is to remove lignin from the pulp to produce high quality fiber and paper. ${ }^{11,12}$ Besides high-volume wood productivities, one of the main targets of eucalypt breeding programs is to increase the $S / G$ ratio to reduce processing costs and enhance the quality of end-products. ${ }^{13}$ Measuring wood properties in large numbers of individuals sampled in progeny and clonal trials along breeding programs is a laborious and expensive endeavor. Near infrared (NIR) spectroscopy for rapid and inexpensive wood phenotyping has therefore been an extremely useful tool in operational tree breeding. ${ }^{14}$

Bench spectrometers are often equipped with interferometers that have better optical properties than the portable ones. They are superior on signal-to-noise ratio, sensitivity and optical resolution. ${ }^{15}$ Besides, they can be used for several years allowing the production of more robust models. Although they are expensive, bench instruments are becoming smaller and less expensive. ${ }^{16}$ On the other hand, portable instruments provide new applications, especially the possibility of in situ acquisition, offer a larger number of different technical specifications, are usually smaller, easier to use, have a simple user interface, are ergonomically designed and cheaper. ${ }^{15}$

The objective of this work was to compare the performance of spectra acquired with a bench and a portable spectrometer of wood dust samples of two Eucalyptus species (E. pellita and E. benthamii). Performance was evaluated by the discrimination power using geometric and multivariate analysis. The spectra analysis will later be correlated with ongoing chemical analysis carried out on a sample subset selected based on the most representative spectra.

\section{Materials and methods \\ Sample collection and preparation}

This study was carried out on progeny trials of E. benthamii and E. pellita that are part of a pilot genomic selec- tion-based breeding program of EMBRAPA (Brazilian Agricultural Research Corporation). ${ }^{17}$ The E. benthamii progeny trial, established with 40 seed sources from wild Australian populations, and four bulked seed sources, was planted in May 2007 in Candói, PR, Brazil. The experiment was thinned following 25 heavy frosts recorded. The remaining 508 trees were ultimately sampled at age 56 months for growth and wood samples collected. The E. pellita breeding trial was composed of 24 open pollinated families derived from a second-generation clonal seed orchard located in Mareeba, Queensland, Australia planted in February 2010 in Rio Verde, GO, Brazil. Phenotypic evaluations were carried out at age 42 months for growth and wood samples collected. Sawdust samples from individual trees were collected using a power drilling machine $(40 \mathrm{~cm}$ long, $1 / 2$ inch diameter), at diameter at breast height $(1.3 \mathrm{~m})$, all in the same geographical orientation. The bark was removed and the sawdust was collected and stored in paper bags for drying. Afterwards, the sawdust samples were individually ground and sifted with a 32 mesh $(500 \mu \mathrm{m})$ screen and stored in capped Falcon tubes to prevent both contamination and humidity variation.

\section{Spectra acquisition}

The 1200 sawdust samples collected, were individually placed in ring cups and the spectra acquired in both bench and portable spectrometer on the same day. We used the bench instrument, FOSS NIRSystems 5000 (1100-2500 nm, $2 \mathrm{~nm}$ intervals) with two readings per sample and the portable spectrometer, Viavi (JDSU) MicroNIR ${ }^{T M} 1700$ (908-1676 nm, 6 nm intervals) with three readings per sample.

\section{Data analysis}

Data from both instruments were analyzed separately using The Unscrambler $X^{\circledR}$ (version 10.2) software. First, a plotline from the raw data was generated to identify and remove any outlier, and the data was analyzed as follows. i) Principal component analysis (PCA) performed with 11 components; ii) linear discriminant analysis (LDA); and iii) partial least square for discriminant analysis (PLS-DA). ${ }^{13,15}$ In order to improve the results, some data transformations were applied to the spectral data. The main data treatment used were standard normal variate (SNV), multiplicative scatter correction (MSC), Detrend, first and second derivatives using Savitzky-Golay method (4 $4^{\text {th }}$-order polynomial fit, 25 


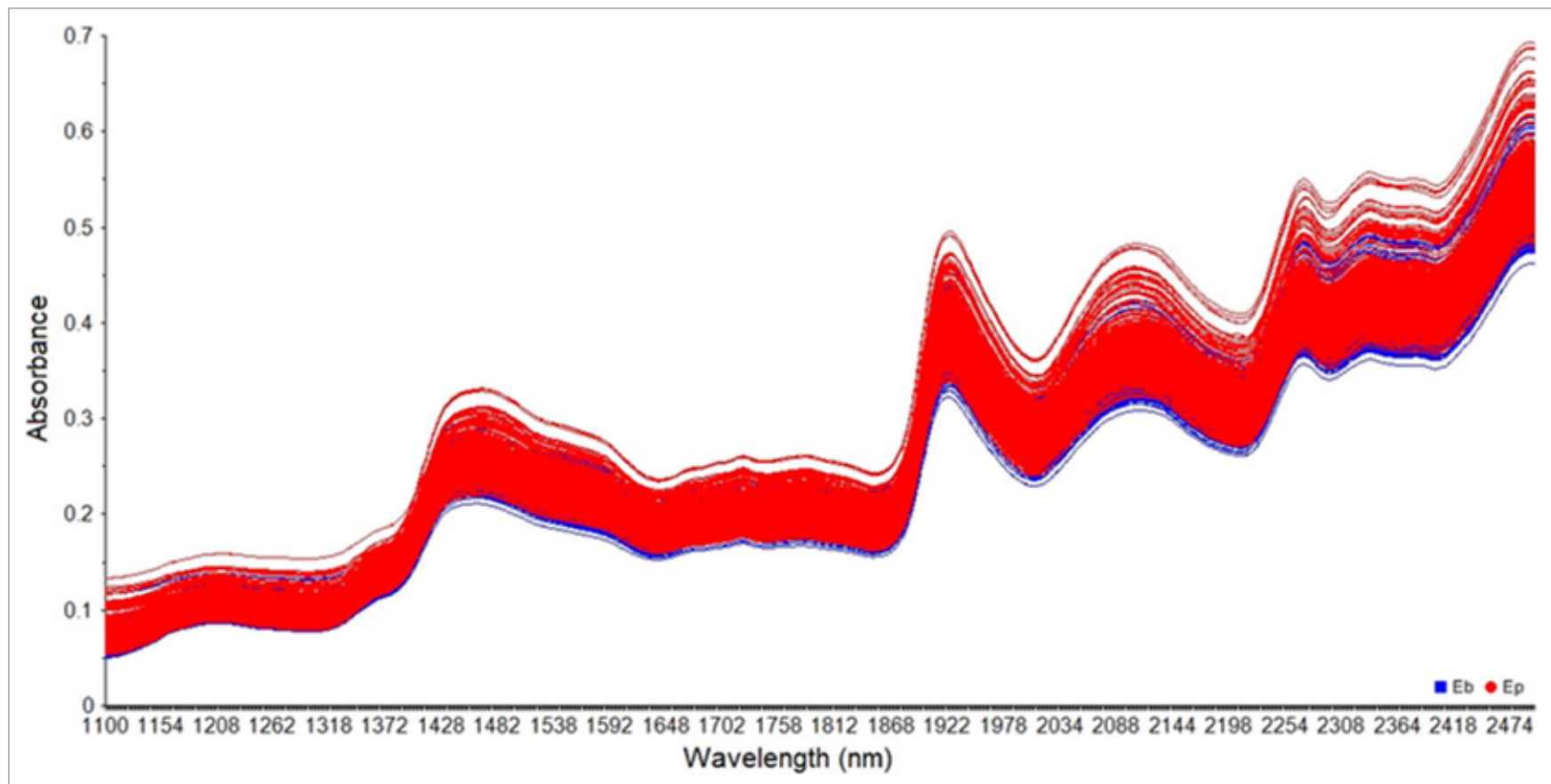

Figure 1. NIR spectra ( $n=2440)$ of Eucalyptus species from bench spectrometer (FOSS NIRSystems 5000).

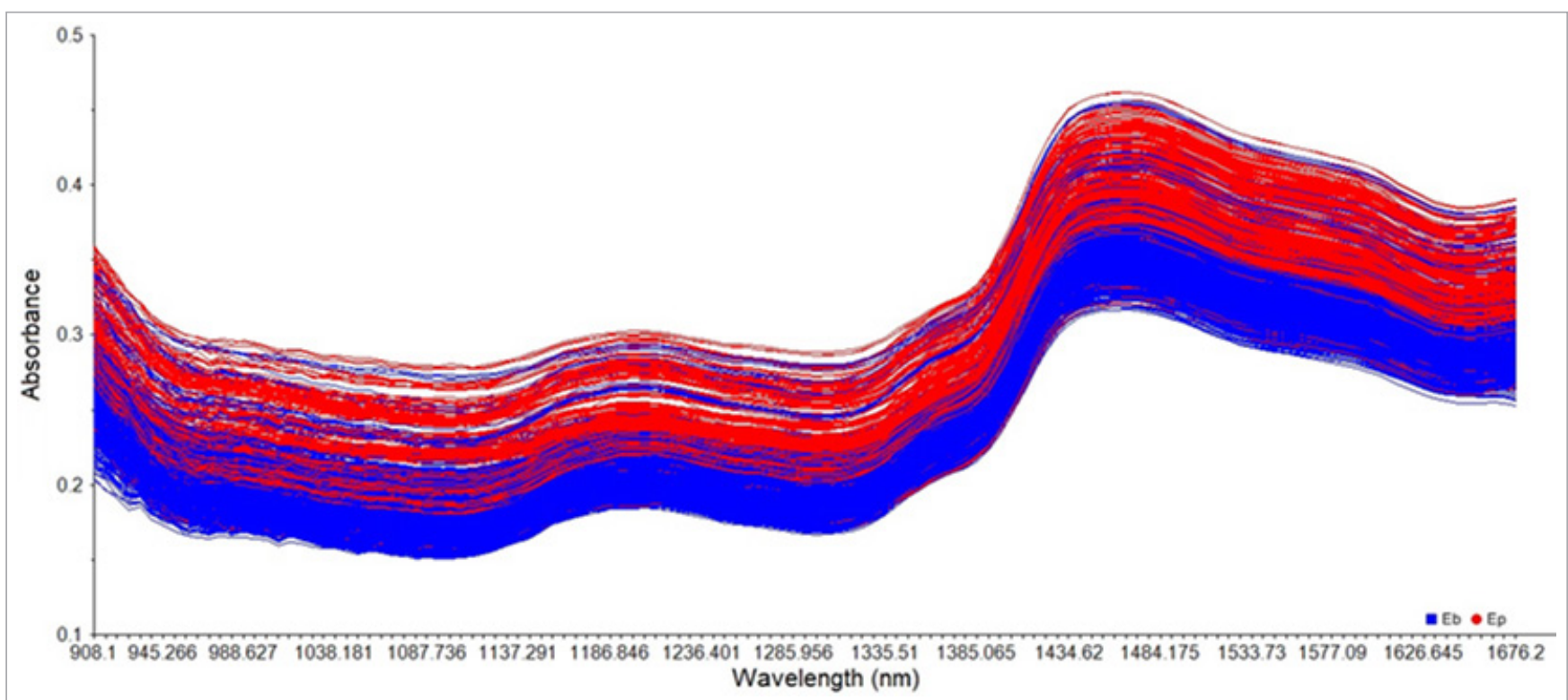

Figure 2. NIR spectra $(n=3660)$ of Eucalyptus species from portable spectrometer (Viavi MicroNIR1700).

smoothing points). ${ }^{15,18}$ Spectra from the bench spectrometer were also analyzed for a shorter region (from $1100 \mathrm{~nm}$ to $1676 \mathrm{~nm}$ ), that overlaps with the range of the portable instrument and displays some variables found to show correlation to some wood traits like lignin $(1672 \mathrm{~nm})$, cellulose $(1428,1488 \text { and } 1590 \mathrm{~nm})^{19}$ and extractives (1434-1477 nm, 1626-1694 nm and $1000-2500 \mathrm{~nm}) .^{20}$

\section{Results and discussion}

\section{Spectra analysis}

A total of 6100 spectra were acquired, 2440 with the bench and 3660 with the portable one (Figures 1 and 2). Spectra appeared to be homogenous and did not separate the two species (data not shown). 


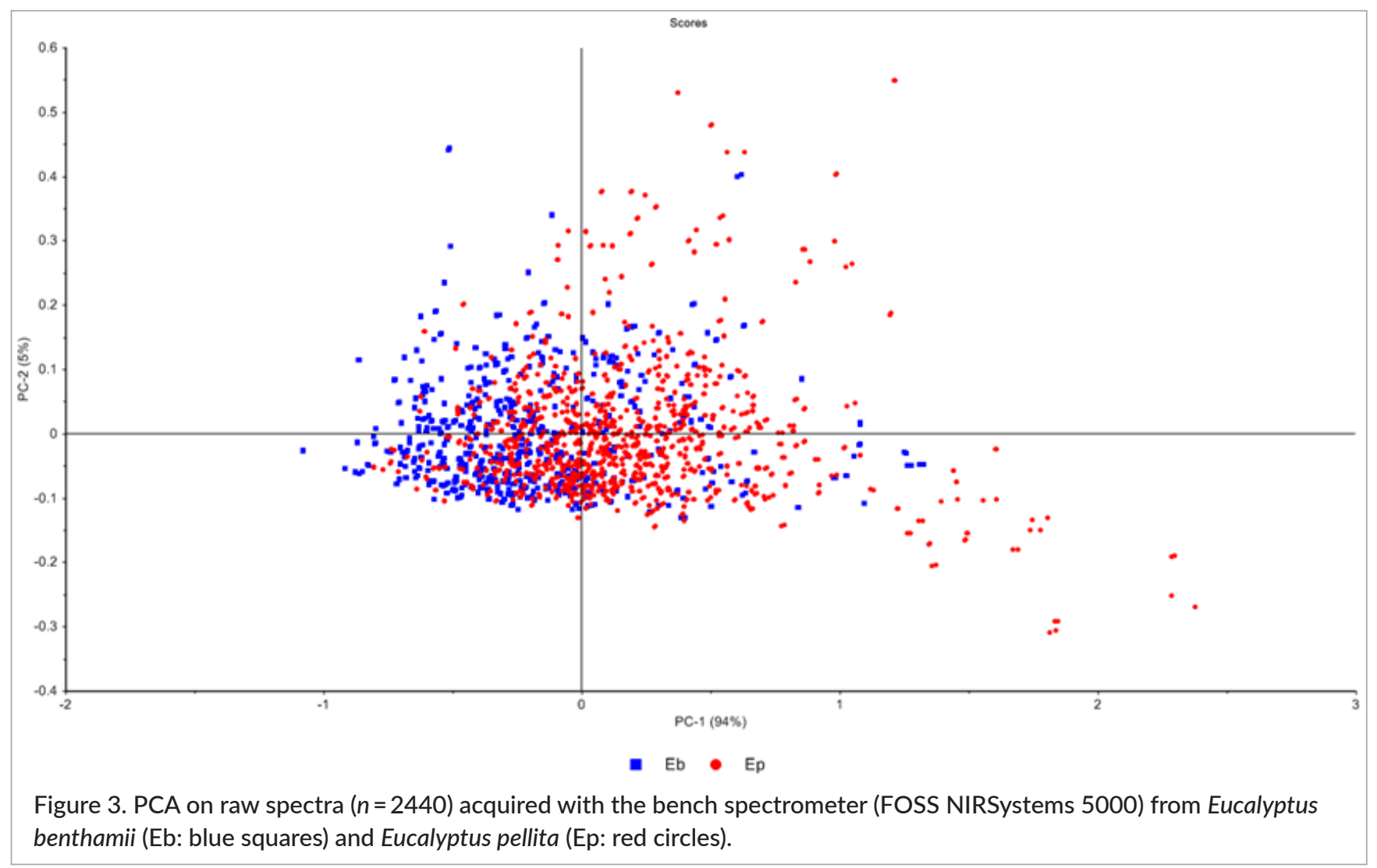

The overlapping spectra (Figures 1 and 2) were not surprising given the phylogenetic proximity of the two species that despite grouped in different sections, belong to the same subgenus (Symphyomyrtus). ${ }^{2}$ Wood species from more distant taxonomic units such as different families or genera usually present different spectral profiles. ${ }^{21}$

The spectra from the portable instrument showed a broader profile, with a smaller number of peaks, again not surprising given the larger range of the bench instrument (1100-2498 nm) when compared to the one of the portable NIR (908-1676 nm). Besides, a larger human interference is likely in the portable Viavi instrument because of the necessary handling to acquire the closer reading of each sample.

\section{Principal component analysis (PCA)}

The PCA for untransformed spectra from both the bench and the portable spectrometers explained around 99\% of the variance, with the two first components explaining $94 \%$ and $5 \%$, and $89 \%$ and $9 \%$, respectively. These PCA did not discriminate the wood samples of two species (Figures 3 and 4). The different treatments applied to the spectra reduced the explained variance for the two first components on the bench and portable spectrometers from $99 \%$ to $80 \%$ and from $98 \%$ to $86 \%$, respectively, for both SNV and MSC (data not shown). This demands a higher number of components to explain the variance of spectral information on treated spectra, which corrected some noise from the samples or the instruments. However, these treatments still did not separate the species analyzed. Even using only spectra for regions corresponding to specific wood chemical components [lignin, syringyl to guaiacyl (S/G) ratio, cellulose, and extractives] it was not possible to separate these species, suggesting that the two species despite their contrasting ecological adaptation profiles, show relatively overlapping wood chemical properties although with clear extremes even in the PCA (Figures 3 and 4). The use of spectra regions for specific wood components did not improve the results of spectra profile, LDA, and PLS-DA.

\section{Linear discriminant analysis (LDA)}

LDA on the other hand allowed good discrimination of the samples of the two Eucalyptus species. Data from the bench spectrometer showed the best results in the LDA with and without data transformation with accuracies higher than 96\% (Table 1). The highest accuracy (99.14\%) with the first derivative followed by Detrend 


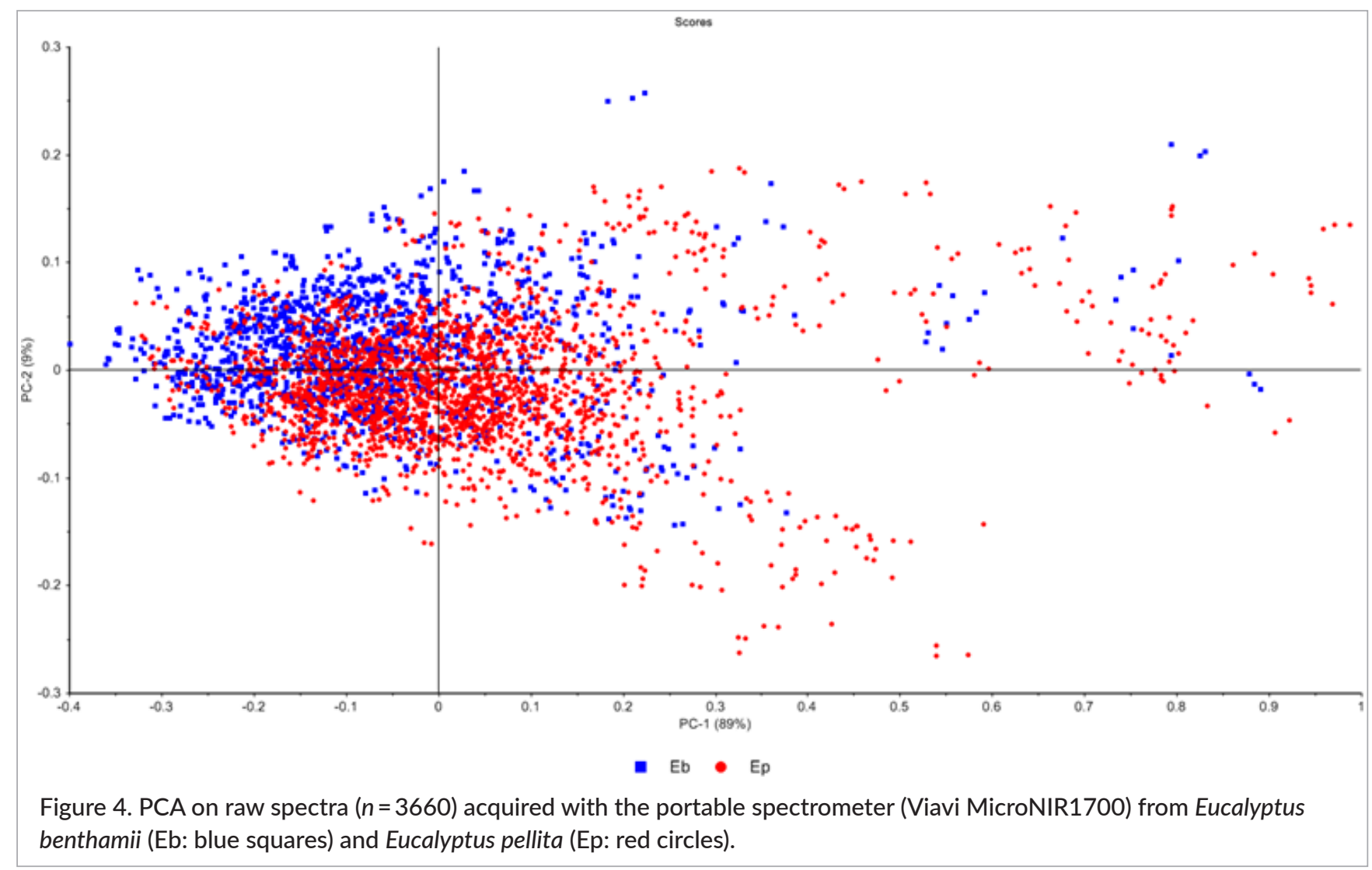

resulted that among all 484 E. benthamii and 736 E. pellita samples analyzed, only 11 and 16, respectively, were not correctly assigned to their respective species. However, it was not statistically significant for the untreated spectra (97.46\%), when 31 samples were mismatched.

Portable spectrometer data analyses for treated spectra presented, however, a slightly lower accuracy (from $86.49 \%$ to $93.45 \%$ ) although statistically significant ( Test, $a=5 \%$ ). The untreated spectra presented $90.83 \%$ accuracy, with 112 samples not correctly assigned. In the data set transformed, slightly higher accuracies were obtained (from $91.24 \%$ to $93.45 \%$ ), resulting in a mismatch of 99 and 98 samples, respectively. Even though data transformations increased slightly the accuracy, it was not statistically significant.

Furthermore, spectra from the short wavelength range (1100-1676 nm) were extracted with the bench spectrometer and LDA performed to approximate the range used by the portable spectrometer. The results were similar to those obtained with the whole spectra (1100$2498 \mathrm{~nm}$ ) and were still better than those obtained from the portable spectrometer (data not shown). This result suggests that the use of higher wavelengths will not result in a better discrimination. Likewise, the slight increase in accuracies of both instruments after data treatment underlines that the wavelength and handling

Table 1. LDA from spectral data acquired in bench $(n=2440)$ and portable $(n=3660)$ spectrometer from E. pellita and E. benthamii.

\begin{tabular}{|l|c|c|c|c|c|c|}
\hline $\begin{array}{l}\text { Spectrometer } \\
\text { accuracy (\%) }\end{array}$ & Raw & SNV & MSC & Detrend & $1^{\text {st } D(S-G)}$ & $2^{\text {nd }}$ D (S-G) \\
\hline Bench & $97.46 a$ & $98.61 \mathrm{a}$ & $98.61 \mathrm{a}$ & $98.69 \mathrm{a}$ & $99.14 \mathrm{a}$ & $95.57 \mathrm{~b}$ \\
\hline Portable & $90.83 \mathrm{c}$ & $91.86 \mathrm{c}$ & $91.97 \mathrm{~b}$ & $91.24 \mathrm{c}$ & $93.45 \mathrm{~b}$ & $86.49 \mathrm{c}$ \\
\hline
\end{tabular}

SNV: standard normal variate; MSC: multiple scatter correction; D: derivative; S-G: Savitzky-Golay. Different lowercase letters (a-c) indicate significant differences using Student $t$ test $(p<0.05)$. 
Table 2. PLS-DA from spectra $(n=2440)$ acquired on bench spectrometer (FOSS NIRSystems 5000 ) in classification of E. pellita and E. benthamii.

\begin{tabular}{|c|l|l|l|l|l|c|c|}
\hline \multicolumn{2}{|c|}{ Data transformation } & Raw & SNV & MSC & Detrend & $1^{\text {st }} D(S-G)$ & $2^{\text {nd }} D(S-G)$ \\
\hline \multirow{4}{*}{ Calibration } & Correlation & 0.951 & 0.964 & 0.963 & 0.958 & 0.970 & 0.957 \\
\cline { 2 - 8 } & $R^{2}$ & 0.905 & 0.928 & 0.928 & 0.917 & 0.942 & 0.915 \\
\cline { 2 - 8 } & SEC & 0.151 & 0.131 & 0.131 & 0.141 & 0.118 & 0.143 \\
\hline \multirow{3}{*}{ Validation } & Correlation & 0.950 & 0.960 & 0.960 & 0.955 & 0.969 & 0.955 \\
\cline { 2 - 8 } & $R^{2}$ & 0.903 & 0.922 & 0.922 & 0.912 & 0.939 & 0.913 \\
\cline { 2 - 8 } & SECV & 0.153 & 0.137 & 0.136 & 0.145 & 0.121 & 0.145 \\
\hline
\end{tabular}

SNV: standard normal variate; MSC: multiple scatter correction; D: derivative; S-G: Savitzky-Golay; $R^{2}$ : coefficient of determination; SEC: standard error of calibration; SECV: standard error of cross validation.

Table 3. PLS-DA from spectra $(n=3660)$ acquired on portable spectrometer (Viavi MicroNIR1700) in classification of E. pellita and E. benthamii.

\begin{tabular}{|l|l|c|c|c|c|c|c|}
\hline \multicolumn{2}{|c|}{ Data transformation } & Raw data & SNV & MSC & Detrend & $1^{\text {st }} D(S-G)$ & $2^{\text {nd }} D(S-G)$ \\
\hline \multirow{3}{*}{ Calibration } & Correlation & 0.898 & 0.897 & 0.898 & 0.880 & 0.879 & 0.878 \\
\cline { 2 - 8 } & $R^{2}$ & 0.806 & 0.808 & 0.807 & 0.774 & 0.772 & 0.771 \\
\cline { 2 - 8 } & SEC & 0.216 & 0.215 & 0.215 & 0.233 & 0.233 & 0.234 \\
\hline \multirow{3}{*}{ Validation } & Correlation & 0.894 & 0.895 & 0.895 & 0.875 & 0.877 & 0.874 \\
\cline { 2 - 8 } & $R^{2}$ & 0.799 & 0.802 & 0.801 & 0.765 & 0.770 & 0.763 \\
\cline { 2 - 8 } & SECV & 0.219 & 0.218 & 0.218 & 0.237 & 0.235 & 0.238 \\
\hline
\end{tabular}

SNV: standard normal variate; MSC: multiple scatter correction; D: derivative; S-G: Savitzky-Golay; $R^{2}$ : coefficient of determination; SEC: standard error of calibration; SECV: standard error of cross validation.

to acquire the spectra were not responsible for the better performance of the bench instrument.

\section{Partial least square regression for discriminant analysis (PLS-DA)}

According to the parameters used to evaluate the PLS-DA, the bench spectrometer was statistically better ( $t$ Test, $5 \%$ ) than the portable one (Table 2 and 3). PLS-DA for the bench spectrometer (Table 2) showed both a higher correlation and coefficient of determination $\left(R^{2}\right)$, and both a lower standard error of calibration (SEC) and cross validation (SECV). Spectra treated with the first derivative with S-G showed the best results $\left(R_{c a l}^{2}=0.942\right.$ and $\left.R_{\text {val }}^{2}=0.939\right)$, very close to SNV and $\operatorname{MSC}\left(R_{\text {cal }}^{2}=0.928\right.$ and $R_{v a l}^{2}=0.922$; for both). The first derivative with S-G treatment was also the best with the LDA.

On the other hand, spectra acquired with the portable spectrometer (Table 3), showed a lower correlation and a larger standard error. The best results were from data transformed by SNV $\left(R_{\text {cal }}^{2}=0.808\right.$ and $\left.R_{\text {val }}^{2}=0.802\right)$, MSC
$\left(R_{\text {cal }}^{2}=0.807\right.$ and $\left.R_{\text {val }}^{2}=0.801\right)$ and raw data $\left(R_{\text {cal }}^{2}=0.806\right.$ and $\left.R_{\text {val }}^{2}=0.799\right)$. Detrend and both first and second derivatives (Savitzky-Golay) showed lower correlations, with $R_{\text {cal }}^{2}$ ranging from 0.771 to 0.774 , while SEC and SECV ranged between 0.215 and 0.238 .

\section{Conclusion}

A comparative performance analysis of a bench and a portable near infrared spectrometer for measuring wood samples of two Eucalyptus species (E. pellita and E. benthamii) was carried out on a large set of 1200 sawdust samples from field trees sampled in progeny trials. Although it is indisputable that the bench instrument had an overall better performance, the portable instrument had a very satisfactory performance given its intrinsic limitations and handling needs. PCA on spectra data from both spectrometers was not able to discriminate the samples of the two species. The portable spectrometer 
had a higher scatter profile which likely reflects its lesser robustness and the necessary handling during spectra acquisition. LDA and PLS-DA on data from the bench spectrometer provided statistically better results than those obtained with data from the portable instrument. For most parameters estimated in this study, the bench spectrometer provided 7-10\% higher accuracies and correlations when compared to the portable instrument. These results were observed with and without spectral transformation, and also using known spectral regions for specific wood chemical components. At the end, a slight improvement was observed on parameters analyzed (accuracies, $r, R^{2}$, SEC and SECV) in both instruments. The chemical analysis currently in progress will allow further and more in-depth assessments on the comparative ability of the two instruments to effectively predict specific wood chemical traits relevant to tree breeding.

\section{Acknowledgment}

We thank Dr Tereza Pastore from the Laboratory of Forest Products and Professor Dr Jez Braga (University of Brasilia, Chemistry Department) for the availability of the Viavi MicroNIR1700 used in this work acquired through Conselho Nacional de Desenvolvimento Científico e Tecnológico (CNPq), project number 473936/2013-5. We also thank Coordenação de Aperfeiçoamento de Pessoal de Nível Superior for the scholarship provided during the masters course for the first author and Fundação de Apoio à Pesquisa do Distrito Federal for the sponsorship to attend the ICNIRS 2017. We also acknowledge Paulo E.T. Santos and Estefano Paludzyszyn Filho of Embrapa Forestry Center for providing the raw wood samples for this study. This work was also supported by PRONEX-FAP-DF grant 2009/00106-8 'NEXTREE', CNPq grant 400663/2012-0 and EMBRAPA grant 03.11.01.007.00.00 to DG. DG had a research fellowship from CNPq.

\section{References}

1. The Plant List, http://www.theplantlist.org/ (2013) [accessed 18 October 2017].

2. M.I.H. Brooker, "A new classification of the Genus Eucalyptus L'Hér. (Myrtaceae)", Aust. Systematic
Bot. 13, 79-148 (2000). https://doi.org/10.1071/ SB98008

3. G.D.S.P. Rezende, M.D.V. de Resende and T.F. de Assis, "Eucalyptus breeding for clonal forestry", in Challenges and Opportunities for the World's Forests in the 21st Century. Springer, Dordrecht, Forestry Sciences Vol. 81, pp. 393-424 (2014). https://doi. org/10.1007/978-94-007-7076-8_16

4. R. Arnold, B. Li, J. Luo, F. Bai and T. Baker, "Selection of cold-tolerant Eucalyptus species and provenances for inland frost-susceptible, humid subtropical regions of southern China", Austr. Forestry 78, 180-193 (2015). https://doi.org/10.1080/00049158 .2015 .1063471

5. C.E. Harwood, D. Alloysius, P. Pomroy, K.W. Robson and M.W. Haines, "Early growth and survival of Eucalyptus pellita provenances in a range of tropical environments, compared with E. grandis, E. urophylla and Acacia mangium", New Forests 14, 203-219 (1997). https://doi.org/10.1023/A:1006524405455

6. L.M.S. Guimarães, M. Titon, D. Lau, L.N. Rosse, L.S.S. Oliveira, C.C.G. Rosado, G.G.O. Christo and A.C. Alfenas, "Eucalyptus pellita as a source of resistance to rust, ceratocystis wilt and leaf blight", Crop Breed. Appl. Biotech. 10, 124-131 (2010).

7. Ö.P. Çetinkol, A.M. Smith-Moritz, G. Cheng, J. Lao, A. George, K. Hong, R. Henry, B.A. Simmons, J.L. Heazlewood and B.M. Holmes, "Structural and chemical characterization of hardwood from tree species with applications as bioenergy feedstocks", PLoS ONE 7, e52820 (2012). http://doi.org/10.1371/ journal.pone.0052820

8. J. Rencoret, A. Gutiérrez, L. Nieto, J. JiménezBarbero, C.B. Faulds, H. Kim, J. Ralph, A.T. Martínez and J.C. del Río, "Lignin composition and structure in young versus adult Eucalyptus globulus plants", Plant Physiol. 155, 667-682 (2011). https://doi. org/10.1104/pp.110.167254

9. A. van Heiningen, "Converting a kraft pulp mill into an integrated forest biorefinery", Pulp \& Paper Canada 107, T141-146 (2006).

10. Food and Agriculture Organization of the United Nations, Statistical Yearbook - Latin America and the Caribbean Food and Agriculture. FAO Publications, Santiago, Chile (2014).

11. J.C. del Río, A. Gutiérrez, I.M. Rodríguez, D. Ibarra and Á.T. Martínez, "Composition of non-woody plant lignins and cinnamic acids by Py-GC/MS, Py/TMAH 
and FT-IR", J. Anal. Appl. Pyrolysis 79, 39-46 (2007). https://doi.org/10.1016/j.jaap.2006.09.003

12. P. Ramadevi, D.V. Hegde, M. Varghese, R. Kamalakannan, S.P. Ganapathy and D.S. Gurumurthy, "Evaluation of lignin syringyl/ guaiacyl ratio in Eucalyptus camaldulensis across three diverse sites based on near infrared spectroscopic calibration modelling with five Eucalyptus species and its impact on Kraft pulp yield", J. Near Infrared Spectrosc. 24, 529-536 (2016). https://doi. org/10.1255/jnirs.1251

13. H. Baillères, F. Davrieux and F. Ham-Pichavant, "Near infrared analysis as a tool for rapid screening of some major wood characteristics in a Eucalyptus breeding program", Ann. For. Sci. 59, 479-490 (2002). https://doi.org/10.1051/forest:2002032

14. C.A. Raymond and L.R. Schimleck, "Development of near infrared reflectance analysis calibrations for estimating genetic parameters for cellulose content in Eucalyptus globulus", Can. J. For. Res. 32, 170-176 (2002).

15. C.A.T dos Santos, M. Lopo, R.N.MJ Páscoa, J.A. Lopes, "A review on the applications of portable near-infrared spectrometers in the agro-food industry", Appl. Spectrosc. 67, 1215-1233 (2013). https:// doi.org/10.1366/13-07228

16. H. Mark and M. Bradley, "Review of new spectroscopic instrumentation for 2016", Spectroscopy 31, 40-62 (2016).
17.B.S.F. Müller, L.G. Neves, J.E. de Almeida Filho, M.F.R. Resende Jr, P.R. Muñoz, P.E.T. dos Santos, E. Paludzyszyn Filho, M. Kirst and D. Grattapaglia, "Genomic prediction in contrast to a genome-wide association study in explaining heritable variation of complex growth traits in breeding populations of Eucalyptus", BMC Genomics 18, 524 (2017). https:// doi.org/10.1186/s12864-017-3920-2

18.J.S. Lupoi, S. Singh, B.A. Simmons and R.J. Henry, "Assessment of lignocellulosic biomass using analytical spectroscopy: an evolution to high-throughput techniques", Bioenerg. Res. 7, 1-23 (2014). https://doi. org/10.1007/s12155-013-9352-1

19. A. Sandak, J. Sandak and M. Negri, "Relationship between near-infrared (NIR) spectra and the geographical provenance of timber", Wood Sci. Technol. 45, 35-48 (2011). https://doi.org/10.1007/s00226$\underline{010-0313-y}$

20. A.M.M. Alves, R.F.S. Simões, C.A. Santos, B.M. Potts, J. Rodrigues and M. Schwanninger, "Determination of Eucalyptus globulus wood extractives content by near infrared-based partial least squares regression models: comparison between extraction procedures", J. Near Infrared Spectrosc. 20, 275-285 (2012). https://doi.org/10.1255/jnirs.987

21. S. Tsuchikawa, K. Inoue, J. Noma and K. Hayashi, "Application of near-infrared spectroscopy to wood discrimination", J. Wood Sci. 49, 29-35 (2003). https://doi.org/10.1007/s10086-002-0471-0 